\title{
Why measure troponin after a fall in the elderly? Results of a prospective study in internal medicine
}

\author{
Caroline Nguyen*, Sandrine Pruvot, Jean François. Bergmann, Guy Simoneau, Isabelle Mahé* \\ Service de Médecine Interne, Hopital Louis Mourier, Université Paris 7, APHP, 178 rue des Renouillers, 92700 Colombes, France
}

\begin{abstract}
Background: Falling is a frequent problem, especially amongst elderly people, causing an increase in mortality. Risen troponin levels reflect myocardial damage but do not always indicate Acute Coronary Syndrome (ACS). The objective of this study was to assess the incidence of high troponin levels amongst people who have fallen. The secondary objectives were to define causes of the fall and provide suggestions as to appropriate management in patients who have fallen and have high troponin levels.
\end{abstract}

Methods: This was a prospective, descriptive study, over 18 months. Measurement of troponin Ic levels, an ECG and a clinical examination were carried out daily for three consecutive days, on patients hospitalised after falling. Follow-up was made during 3 days then at 6 months after the patients were discharged.

Results: Fifty five patients were included. The incidence of high troponin levels was 38\%, and in patients with high levels, $24 \%$ were diagnosed with ACS. In other patients, troponin increase was related to heart failure, pericarditis, sepsis or stroke. The troponin level was significantly higher within the three days of an ACS. The 6 month mortality among patients with high levels of troponin was doubled (57.1\% versus $23.5 \%)$. There was no correlation between creatinine clearance and troponin levels.

Conclusions: High levels of troponin after falls help in diagnosis. The troponin level was highest in cases of ACS. Six month mortality was increased in cases with raised troponin. Troponin measurement can guide physicians in their daily practice.

\section{Introduction}

Falls are very frequent in elderly patients: $33 \%$ of people older than 65 and more than half of those older than 85 years fall at least once a year. Falls have serious consequences in this frail population [1], often leading to hospitalisation [2], even if programs for falls prevention exist [3], and there is an increased risk of death [4] during the year following the fall, estimated at $8 \%$ of the patients [5-7]. The causes of falls are countless and multifactorial $[8,9]$.

Clinically, we commonly observe that serum cardiac troponin is increased after a fall, without any clinical or ECG evidence of Acute Coronary Syndromes (ACSs). Since 2012 [10], it has been recognised that serum cardiac troponin is the gold standard for detection and diagnosis of ACS: it is not detected in healthy people's serum, is only released into the circulation if there is myocardial injury. The cardiac troponin level begins to rise from 4 to 6 hours after the onset of the symptoms [11] and it remains detectable from to 10 days after the damage has occurred.

Although a raised troponin level indicates myocardial damage, it does not reveal the mechanism [12]. Troponin levels have also been reported to increase in various clinical situations apart from ACS $[13,14]$, with the evolution of the level differing according to the diagnosis: during an acute coronary syndrome and a cerebral stroke, the level rises slowly then decreases. This "troponin cycle" defines the type of ischaemia [15]; in other diseases, such as sepsis and myopericarditis, the troponin level only decreases.

Creatine phosphokinase MB (CPK-MB) is also specific to the myocardium, but is less sensitive in the diagnosis of ACS, with levels decreasing more rapidly after the injury. Creatine phosphokinases (CPKs) as a class are of muscular origin, and therefore their levels logically rise after a person falls, due to muscular damage.

It is sometimes difficult to explain why there is an increased level of troponin after a fall. In practice, physicians are often unsure as to its significance in this context, and it is usually attributed to the fall alone. However, this may result in other factors being ignored. The objective of this study was therefore to evaluate the prevalence of raised troponin levels after falls. The secondary objective was to investigate the possible mechanisms involved and to develop a diagnostic flow chart for use when the physician is faced with an unexpected troponin increase in an elderly patient who has fallen.

\section{Materials and methods}

This was a prospective, descriptive study based on clinical, biochemical and ECG follow-up over three consecutive days in patients who had fallen. It was conducted in the Internal Medicine Department at the Lariboisière Hospital, Paris (Assistance Publique

Correspondence to: Caroline Nguyen, Hôpital Louis Mourier, Service de Médecine Interne Université Paris 7, APHP 178 rue des Renouillers, 92700 Colombes, France, E-mail: caroline.ng87@gmail.com

Pr. Isabelle Mahé, MD, PhD, Hôpital Louis Mourier, Service de Médecine Interne Université Paris 7, APHP 178 rue des Renouillers, 92700 Colombes, France, Tel: 00331476064 90; Fax: 00331476064 91; E-mail: isabelle.mahe@lmr.aphp.fr

Key words: fall, elderly, rising troponin, acute coronary syndrome

Received: April 15, 2015; Accepted: May 15, 2015; Published: May 18, 2015 
des Hôpitaux de Paris-Paris 7 University) from June 2002 to November 2003. Patients gave oral and written consent. After asking the ethics committee, there was no need for an ethic committee approval as it is not an interventional study: blood sample was already taken from the patient for other reasons.

\section{Patient characteristics}

Patients were included when they had been hospitalised after a fall at home or having fallen during hospitalisation, whatever the immediate cause of the fall was and without any limit of age. Patients were excluded if they were taken into care more than 24 hours after the fall. Severe renal impairment was defined as a creatinine clearance $<30$ $\mathrm{mL} / \mathrm{min}$ using the Cockcroft formula.

\section{Procedures}

For all patients, demographic data, the time lapse between the fall and the first troponin measurement, the immediate cause of the fall, any cardiovascular risk factors, and the medical history were all recorded. Troponin, CPK and CPK-MB were measured over three consecutive days (D1, D2, D3) from a blood sample taken for any other reason. Every day, patients received a physical examination looking for signs of angina pectoris, congestive heart failure or muscular pain.

A 12 lead ECG was also performed every day to detect myocardial damage during three days; the ECGs were assessed blindly by a cardiologist who was not aware of the troponin level or the patient's clinical signs. All the ECGs were assessed in one batch at the end of the study inclusion period. ECGs were then classified into "myocardial damage", "necrosis signs", "pericarditis", "non interpretable" and "normal".

Troponin Ic $(\mu \mathrm{g} / \mathrm{L})$ was measured using the Abbott Axsym system test (normal level: $<0.4 \mu \mathrm{g} / \mathrm{L}$ ), as was CPK MB (normal level: $<6 \mu \mathrm{g} / \mathrm{L}$ ). The CPKs were measured using the Kodak Ektachem test (normal level: $<170 \mathrm{IU} / \mathrm{L})$.

The primary outcome was the cardiac troponin level. Each patient was classified into one of the five groups representing the most usual diagnosis responsible for an increase in troponin, i.e., acute coronary syndrome, cerebral stroke, heart failure, sepsis, and 'other causes'.

Patients were followed up systematically at 1 and 6 months via a personal phone call, or a telephone call to their general practitioner or the family.

\section{Statistical analysis}

Quantitative variables (troponin, CPK, CPK-MB) were studied according to time and between each group, using analysis of variance (ANOVA) and repeated measures for the factor "time". A nominal variable was constituted by the five groups of patient diagnoses defined a priori (acute coronary syndrome, cerebral stroke, heart failure, sepsis, or other causes), and graded according to severity of the pathology.

Possible relationships between the quantitative variables were analysed using linear correlation testing. A coefficient $r<0.07$ was considered statistically significant.

\section{Results}

\section{Patients}

Overall, 55 patients were enrolled in the study within the 18 month inclusion period. Demographic and clinical population characteristics are detailed in Table 1 . The immediate and finally determined causes of the fall are resumed in Table 1: the data is given overall and also divided into two classes of patients with and without high troponin levels during follow-up on one measurement. Mean age was $78.9+/$ 13.8 years. A history of coronary artery disease was found in 9 patients (16.4\%). Falls were mainly due to mechanical reasons (60\%). During the study period, the troponin level was found to be $>0.4 \mu \mathrm{g} / \mathrm{L}$ in 21 patients $(38 \%)$ and $<0.4 \mu \mathrm{g} / \mathrm{L}$ in 34 patients $(62 \%)$. Three patients (5.5\%) declared having chest pain. Five patients older than 75 years had a confirmed diagnosis of ACS but only one had experienced chest pain. There was a relationship between ACS and the cause of fall but as elderly people often have no symptom when ACS occurs, ACS could incidentally be diagnosed: silent myocardial infarction results in $80 \%$ of ACSs in the patients over 75 years old.

Otherwise, 23 patients (41.8\%) had ECG changes during the three days of follow-up, of which 13 (23.6\%) suggested myocardial damage.

\section{Rise in troponin Ic levels}

The troponin level mainly rose more than $0.4 \mu \mathrm{g} / \mathrm{L}$ during ACS (19\%), acute heart failure (14.3\%), cerebral stroke (19\%) and sepsis (19\%).

The maximum troponin level was significantly higher in patients diagnosed with ACS than those with sepsis $(p<0.0001)$, acute heart failure $(\mathrm{p}<0.0001)$, or without any cardiac cause being found $(\mathrm{p}<0.0001)$ (Figure 1).

Comparison between the different pathologies shows that the mean troponin level in the ACS and ischaemia groups was significantly higher than in the groups with sepsis $(\mathrm{p}=0.0002)$, heart failure $(\mathrm{p}=0.0003)$, cerebral stroke $(p=0.0006)$, or without any cardiac cause $(p=0.0001)$. When analysing the population according to the timing of troponin increase, we found that (1) at Day 1, patients with ACS had a troponin level between 0.5 and $30 \mu \mathrm{g} / \mathrm{L}$; a troponin level $>6 \mu \mathrm{g} / \mathrm{L}$ was observed only in the ACS group, (2) at Day 2, when the troponin level had risen and was more than $1.6 \mu \mathrm{g} / \mathrm{L}, 5$ patients among the 7 patients who had

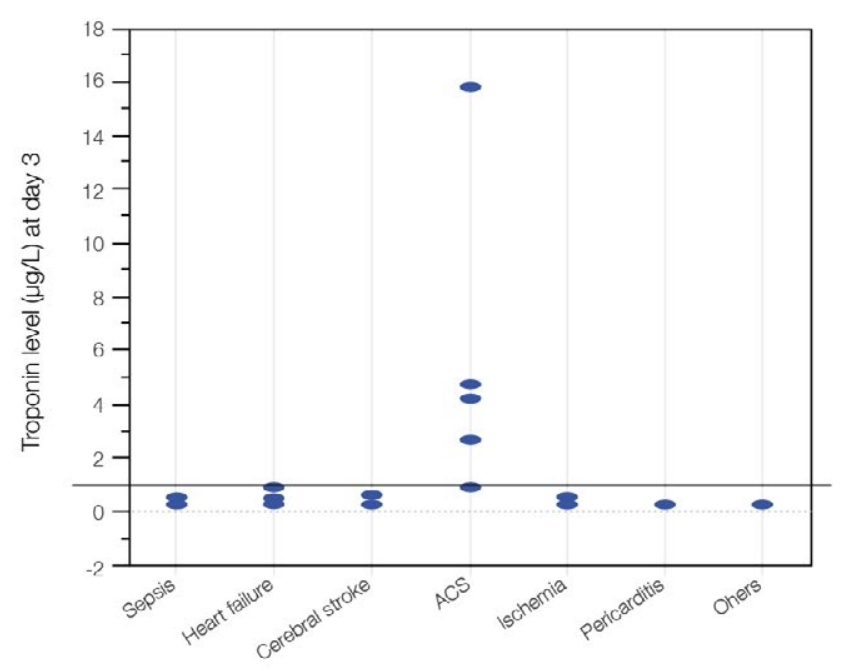

Figure 1. Maximun troponin according to pathology. 
Table 1: Demographic and clinical characteristics of 55 patients hospitalised due to a fall.

\begin{tabular}{|c|c|c|c|c|}
\hline & & Included patients & Troponin $<0.4 \mu \mathrm{g} / \mathrm{L}$ & Troponin $>0.4 \mu \mathrm{g} / \mathrm{L}$ \\
\hline $\mathrm{n}$ & & 55 & 34 & 21 \\
\hline Sex ratio $\mathrm{M} / \mathrm{F}$ & & 0.49 & 0.42 & 0.61 \\
\hline Age & & $78.9+/-13.8$ & $78+/-12$ & $80+/-16.6$ \\
\hline Time to coming into care (hours) & & $17.7+/-6.0$ & $17+/-6.1$ & $17.7+/-6.1$ \\
\hline \multirow{4}{*}{ Immediate cause of fall } & Environmental (tripping, slipping) & $33(60.0 \%)$ & $21(61.8 \%)$ & $12(57.1 \%)$ \\
\hline & Fainting, no loss of consciousness & $12(21.8 \%)$ & $9(26.5 \%)$ & $3(14.3 \%)$ \\
\hline & Fainting, with loss of consciousness & $9(16.4 \%)$ & $3(8.8 \%)$ & $6(28.6 \%)$ \\
\hline & Convulsive convulsion & $1(1.8 \%)$ & $1(2.9 \%)$ & $0(0.0 \%)$ \\
\hline \multirow{6}{*}{ Cardiovascular risk factors } & High blood pressure & $28(50.9 \%)$ & $18(52.9 \%)$ & $10(47.6 \%)$ \\
\hline & Dyslipidaemia & $9(16.4 \%)$ & $7(20.6 \%)$ & $2(9.5 \%)$ \\
\hline & Tobacco & $16(29.1 \%)$ & $8(23.5 \%)$ & $8(38.1 \%)$ \\
\hline & Coronary artery disease & $9(16.4 \%)$ & $5(14.7 \%)$ & $4(19.0 \%)$ \\
\hline & Diabetes mellitus & $9(16.4 \%)$ & $8(23.5 \%)$ & $1(4.8 \%)$ \\
\hline & Age $>55$ years & $50(90.9 \%)$ & $31(91.2 \%)$ & $19(90.5 \%)$ \\
\hline \multicolumn{2}{|l|}{ Chest pain } & $3(5.5 \%)$ & $1(2.9 \%)$ & $2(9.5 \%)$ \\
\hline \multicolumn{2}{|l|}{ Clinical signs of heart failure } & $13(23.6 \%)$ & $5(14.7 \%)$ & $8(38.1 \%)$ \\
\hline \multirow{5}{*}{ ECG } & Myocardial damage & $13(23.6 \%)$ & $5(23.8 \%)$ & $8(38.1 \%)$ \\
\hline & Necrosis & $9(16.4 \%)$ & $6(17.6 \%)$ & $4(19.0 \%)$ \\
\hline & Pericarditis & $1(1.8 \%)$ & $0(0.0 \%)$ & $1(4.8 \%)$ \\
\hline & No interpretation & $9(16.4 \%)$ & $6(17.6 \%)$ & $3(14.3 \%)$ \\
\hline & Normal & $23(41.8 \%)$ & $17(50 \%)$ & $5(23.8 \%)$ \\
\hline \multirow{3}{*}{ Laboratory results } & $\mathrm{CPK}>170 \mathrm{IU} / \mathrm{L}$ & $35(63.6 \%)$ & $18(52.9 \%)$ & $17(80.9 \%)$ \\
\hline & $\mathrm{CPK}-\mathrm{MB}>6 \mathrm{IU} / \mathrm{L}$ & $24(43.6 \%)$ & $10(29.4 \%)$ & $14(66.7 \%)$ \\
\hline & Severe renal failure $\mathrm{Cl}<30 \mathrm{~mL} / \mathrm{min}$ & $10(18.2 \%)$ & $2(5.9 \%)$ & $8(38.1 \%)$ \\
\hline \multirow{13}{*}{ Final diagnosis explaining the fall } & Acute coronary syndrome & $4(7.3 \%)$ & $0(0.0 \%)$ & $4(19.0 \%)$ \\
\hline & Pulmonary embolism & $1(1.8 \%)$ & $0(0.0 \%)$ & $1(4.8 \%)$ \\
\hline & Phlebitis & $1(1.8 \%)$ & $1(2.9 \%)$ & $0(0.0 \%)$ \\
\hline & Congestive heart failure & $7(12.7 \%)$ & $4(11.8 \%)$ & $3(14.3 \%)$ \\
\hline & Cerebral Stroke & $11(20.0 \%)$ & $7(20.6 \%)$ & $4(19.0 \%)$ \\
\hline & Sepsis & $13(23.6 \%)$ & $9(26.5 \%)$ & $4(19.0 \%)$ \\
\hline & Arrhythmia & $2(3.6 \%)$ & $2(5.9 \%)$ & $0(0.0 \%)$ \\
\hline & Pericarditis & $1(1.8 \%)$ & $0(0.0 \%)$ & $1(4.8 \%)$ \\
\hline & Metabolic disorder & $5(9.1 \%)$ & $2(5.9 \%)$ & $3(14.3 \%)$ \\
\hline & Drug side effects & $4(7.3 \%)$ & $4(11.8 \%)$ & $0(0.0 \%)$ \\
\hline & Suicide attempt & $1(1.8 \%)$ & $0(0.0 \%)$ & $1(4.8 \%)$ \\
\hline & Dementia & $3(5.5 \%)$ & $3(8.9 \%)$ & $0(0.0 \%)$ \\
\hline & General alteration in state & $2(3.6 \%)$ & $2(5.9 \%)$ & $0(0.0 \%)$ \\
\hline
\end{tabular}

a troponin level $>1.6 \mu \mathrm{g} / \mathrm{L}$ were diagnosed with ACS (sensitivity $100 \%$, specificity 96\%) and (3) at Day 3, all patients with a troponin level $>0.9$ $\mu \mathrm{g} / \mathrm{L}$ belonged to the ACS group (sensitivity $100 \%$, specificity $98 \%$ )

\section{Rise in CPK levels}

At D1, the CPK level was already raised, but it subsequently decreased. Analysis of its variation over time in the five groups showed 
that there was no significant difference between the groups $(\mathrm{p}=0.46)$. In addition, there was no significant difference when two-by-two comparison was carried out for all possible combinations within the five groups.

The overall analysis of CPK levels according to troponin levels is detailed in Figure 2. Among the patients diagnosed with ACS, there was no correlation between CPK and troponin $\left(\mathrm{R}^{2}=0.03\right)$. The relationship between $\mathrm{CPK}-\mathrm{MB}$ and troponin levels was linearly compatible (i.e., CPK-MB rose when troponin rose) in the ACS group, but the correlation was not close $\left(\mathrm{R}^{2}=0.33\right)$. When the main cause of the fall was not cardiac, high CPK or CPK-MB levels were constantly observed and the troponin level did not rise (apart from in two patients). In the two patients mentioned, who both had a troponin levels $>0.4 \mu \mathrm{g} / \mathrm{L}$, the raised level could be ultimately explained by a cardiac cause.

\section{Troponin and renal failure}

Severe renal failure was detected more often in the group of patients with a high troponin level (38.1\% versus 5.9\%). However, there was no significant correlation between the troponin level and creatinine

Regression plot

$\mathrm{Y}=754,373+12,532{ }^{*} \mathrm{X} ; \mathrm{R}^{\wedge} 2=, 031$

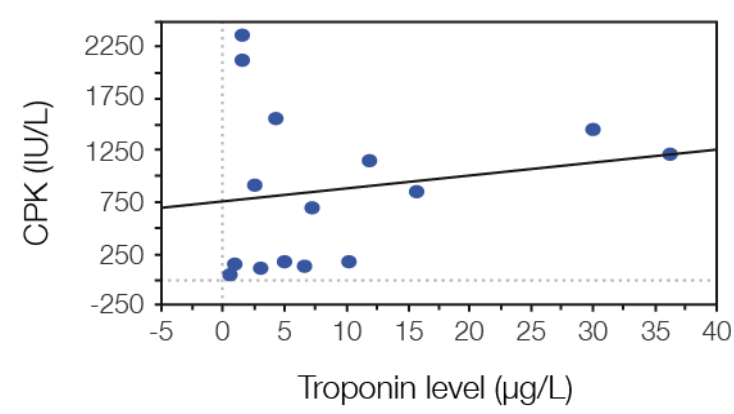

Regression plot

$Y=14,037+1,729 * X ; R^{\wedge} 2=, 038$

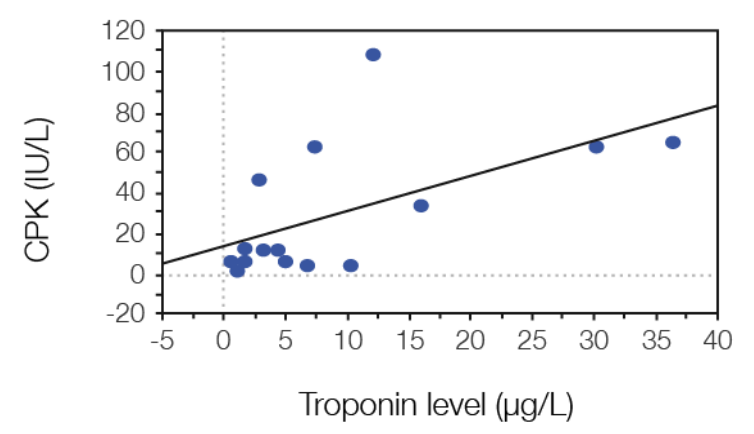

Figure 2. Correlation between CPK, CPR-MB and troponin levels.

\section{Regression Plot Split By : Critères 1 Cell : non}

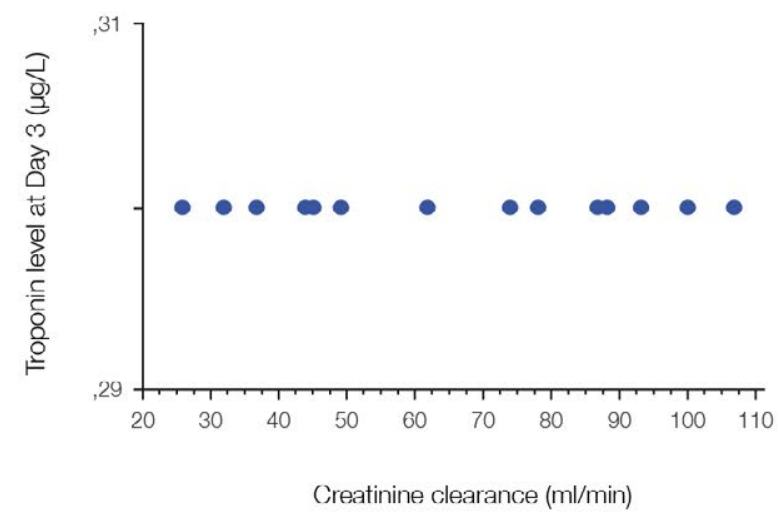

Figure 3. Correlation between troponin level at day 3 and creatinine clearance.

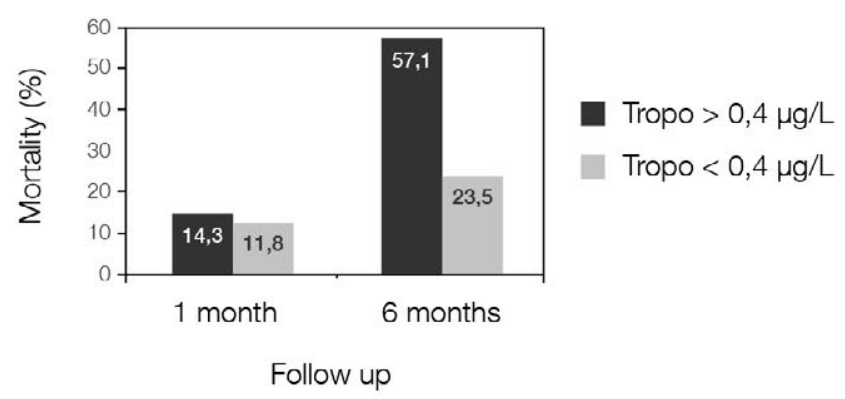

Figure 4. Mortality at 1 month and 6 months according to the maximum troponin level.

clearance $\left(\mathrm{R}^{2}=0.287\right)$ (Figure 3). Troponin level rises independently of the creatinine clearance.

\section{Troponin and mortality}

At 1 month, 7 patients died (12.7\%). At 6 months, 20 patients died (36.4\%). There was no significant difference in the mortality at 1 month between the group of patients with no troponin increase and the group with raised troponin $(11.8 \%$ vs $14.3 \%, \mathrm{p}=0.9)$. The 6 months mortality was double in the group of patients with raised troponin compared to the patients with no troponin increase $(57.1 \%$ vs $23.5 \%, \mathrm{p}=0.01)$ (Figure 4).

\section{Discussion}

Falls among elderly people are a daily reality and a public health problem, often leading to hospitalisation, severe complications and possibly death. In some cases, the cause is not immediately obvious, and more comprehensive investigations, including troponin measurement, are carried out.

The measurement of troponin is now a common practice when ACS is suspected. However, when the level is increased, the question remains as to what to do. Unfortunately, while an increased level reflects undiagnosed cardiac injury and is predictive for adverse outcomes in 
other settings, it is often ignored in cases of falls. As far as we are aware, our study is the first to prospectively assess clinical, biochemical and ECG data during three consecutive days after a fall.

Troponin is now recognised as a specific cardiac marker. A cohort study of 3557 subjects showed that in the general population, cTnT elevation is rare in subjects without heart failure, left ventricular hypertrophy, chronic kidney disease or diabetes mellitus [16].

Our results confirmed that clinical signs often do not help in making a diagnosis after falls, as the majority of ACSs amongst the patients older than 75 years old were silent (80\%). We showed that troponin measurement is of diagnostic interest after falls, with an increase revealing cardiac stress. The kinetics of troponin levels over time (the "troponin cycle") also provide important clues in the diagnosis, as the definition of ACS specifies the rise of troponin to a peak level before decreasing.

Our study highlights the fact that the troponin level can help in identifying the cause of the fall, while emphasising that a raised troponin level does not necessarily indicate ACS [12]. As the 2012 ESC definition of ACS clearly reminds us, an ACS has been defined by three elements: an increase in cardiac biochemical markers (such as cardiac troponin above the $99^{\text {th }}$ percentile); clinical symptoms of ischaemia (such as typical chest pain); and ECG modification (such as ST segment or T wave changes). Another criterion is now included in the definition: identification of an intracoronary thrombus by percutaneous angiography. Therefore, although a rise in troponin is always correlated to myocardial injury, it is not synonymous of ACS [17]. It can be caused by other pathologies such as sepsis, heart failure, pulmonary embolism and more, as seen in our study and several other studies $[15,18]$. First, troponin measurement is helpful for the diagnosis and its level even more: the higher the troponin level is, the more it is correlated to a myocardial necrosis. The lower the troponin level is, the more the diagnosis of non coronary disease is probable. Then, the troponin has a prognosis value. Our results are in accordance with their scheme about the diagnosis and the troponin level.

Our study also highlights that the higher the level of troponin, the more probable the diagnosis of ACS. It appears therefore that the actual troponin level should be taken into account, and not just its positivity. As far as we are aware, this particular point has not yet been studied, and could be an area of future research. There is no cut off to correlate the troponin level with the certain diagnosis of ACS in other studies.

As a raised troponin level reflects the death of cardiomyocytes because the troponin can only be found in cardiomyocytes [16], its raising suggests a cardiac functional or structural abnormality. That's why its presence after a fall must be explained by cardiac injury, and not the fall itself. The cardiac injury is most frequently a result of ACS, sepsis, cerebral stroke, and cardiac failure. During heart failure, sepsis or stroke, myocardial damages often occur without meaning ACS but are not constant in these affections. A retrospective cohort study conducted in the emergency unit of Montfermeil hospital [19] showed that a rise in troponin does not always indicate acute coronary syndrome, but signifies myocardial damage due to heart failure (35\%) or sepsis $(35 \%)$. However, this study limited itself to recording only the medical history, an ECG and one troponin measurement upon the patient's arrival in the emergency unit: there was no clinical, ECG or biochemical marker follow-up.

Two patients in our study had a rise of troponin level while the main cause of the fall was not cardiac. But this rising can still be linked to a cardiac cause. The first patient was hospitaliezd due to voluntary intoxication with a neuroleptic drug. A rise in troponin level is not a recognized effect of this drug. However, cases of elevated troponin have already been reported with other neuroleptics [20,21]. The second patient had a prostatic cancer with associated hypercalcaemia; troponin was moderately increased at Day $1(0.7 \mu \mathrm{g} / \mathrm{L})$ and had returned to normal at Day 2 and Day 3, with no myocardial damage being evident clinically or on ECG. Mild acute heart failure was the most plausible hypothesis explaining this patient's troponin level. One more time, the rising of troponin level can be explained by a cardiac injury.

A prospective observational study performed in 2008 also studied the clinical relevance of a troponin increase in patients who had fallen. Troponin was measured just after the fall and 6 hours later, and clinical, ECG and echographic data were collected. This study also concluded that minor myocardial damage which is detected by cardiac troponin levels correlates with unknown cardiac abnormalities, and appears to be a prognostic indicator in the setting of falls in elderly patients [22]. However, there was no follow-up over the three days following the fall and no aetiological classification was proposed for the troponin elevation.

We found no significant difference in the risk of death at 1 month between the two subgroups of patients with low or high troponin level during follow-up. However, at 6 months, the mortality rate was doubled in the group of patients with raised troponin. Elevated troponin level was therefore a prognostic factor in patients in our study, especially when there was a persistently raised troponin at Day 3 . This can be explained by the link between the prolonged period of released troponin and the importance of myocardial damage. Another study has demonstrated similar findings, showing that there is a higher risk of complications after ACS in patients with raised troponin levels [23]. However, this study's population included patients hospitalised for ACS in a cardiac intensive care unit, with a high risk of complications. The prognostic value of raised troponin has also been demonstrated in other clinical settings, such as cardiac surgery, renal failure, and hip fracture [24].

A cohort study of 1089 asymptomatic elderly men without any heart disease at enrolment showed that a $\mathrm{cTnI} 0.03 \mu \mathrm{g} / \mathrm{L}$ was associated with a hazard ratio of 5.25 for heart failure, compared with persons with cTnI $<0.01 \mu \mathrm{g} / \mathrm{L}$, independently of any other covariate such as N-terminal pro hormone brain natriuretic peptide (NT pro BNP). Even a slight rise in the troponin level $(>0.01 \mu \mathrm{g} / \mathrm{L})$ correlated with a significant risk of developing heart failure (hazard radio of 1.26), adjusted to the NT pro BNP value. That provides additional confirmation of how specific troponin is for heart damage and also its importance in determining the patient's prognosis $[11,25]$.

The prevalence of cardiovascular diseases in chronic kidney failure (CKF) is 3\% [26], and CKF should be considered as a strong cardiovascular risk factor. However, the interpretation of a raised troponin in CKF is confusing. It occurs frequently and without any sign of myocardial damage, leading to the rise often being attributed wrongly to the CKF. The current explanation is that the hyperuricaemia causes a structural alteration in the cardiac muscle, which in turn causes a cascade of left ventricular hypertrophy, myocardial degeneration, endothelial dysfunction with coronary lesions, apoptosis and myocardial inflammation. To further complicate matters, patients with CKF often have associated heart failure which can also explain the rise in troponin [27]. It is demonstrated that a rise in troponin level in end stage renal failure is of worse prognosis (RR 2.64), even without any 


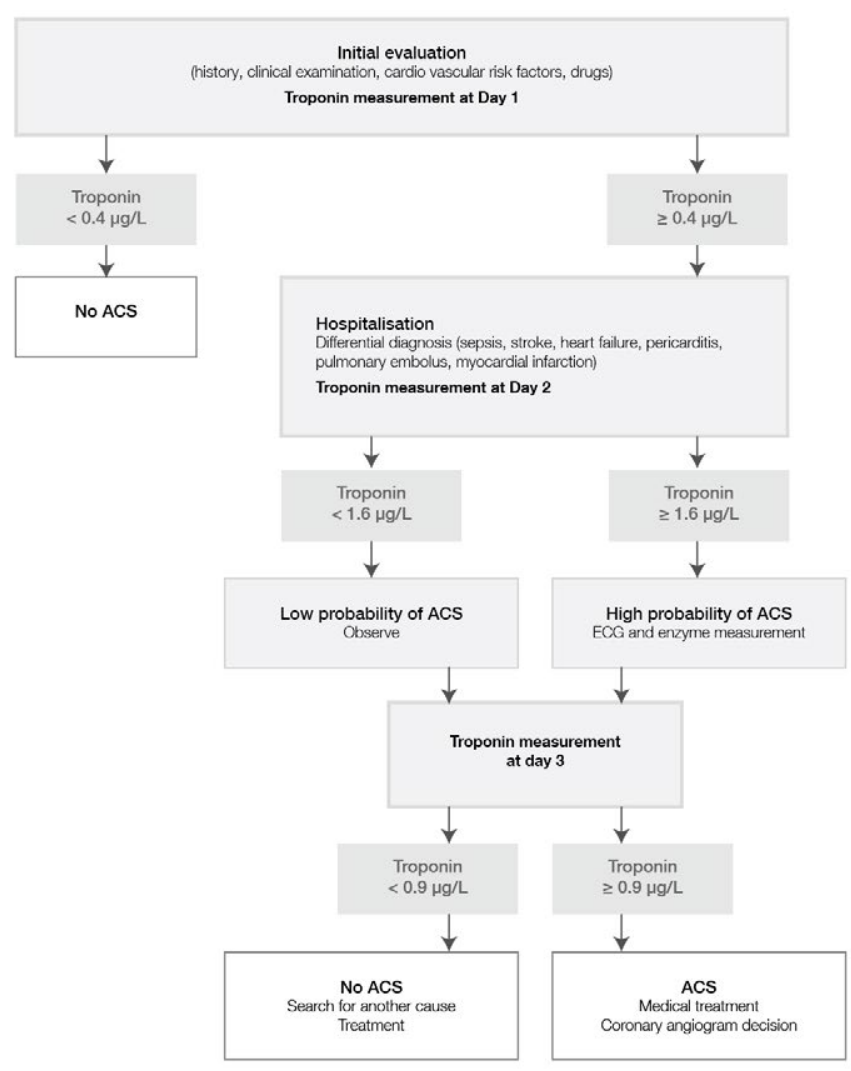

Figure 5. Flow Chart of proposed management of patient who has fallen and with daily troponin measurement.

symptom [28]. In fact, $38 \%$ of our patients with troponin levels $>0.4$ $\mu \mathrm{g} / \mathrm{L}$ had severe renal impairment. A risen troponin level in patients with CKF cannot be interpreted as a defect of the kidney clearance but is a strong marker of cardiac injury.

Our study is limited by the low number of patients and the choice to include patients without age limit. However, the population, as expected, was mainly elderly, with the youngest patient being 65 years old. It therefore gives an insight into this particularly vulnerable group in society. As physicians are often uncertain about how to proceed when faced with a raised troponin level in elderly patients who have fallen, and who do not however have any obvious diagnosis, we have produced a flow chart which we have found to help in such situations (Figure 5).

\section{Conclusion}

A rise in troponin levels after a fall is frequent and is of myocardial origin. Measurement of troponin in such a situation is of diagnostic use, since its level during ACS or ischaemia is significantly higher than during the transitory ischaemia caused by cerebral stroke, sepsis, or heart failure. Its measurement also has prognostic value since we found that at 6 months post-fall, the all-cause mortality was doubled in patients with a troponin level $>0.4 \mu \mathrm{g} / \mathrm{L}$ measured in the three days following the fall. Our study demonstrates the importance of measuring the evolution of troponin levels, combined with an ECG, over three consecutive days.

\section{References}

1. Cumming RG, Salkeld G, Thomas M, Szonyi G (2000) Prospective study of the impact of fear of falling on activities of daily living, SF-36 scores, and nursing home admission. J Gerontol A Biol Sci Med Sci 55: M299-305. [Crossref]

2. Puisieux F (2002) Movement and balance disorders. Falls in the elderly. Rev Prat 52 1695-1702. [Crossref]

3. Perell KL, Nelson A, Goldman RL, Luther SL, Prieto-Lewis N, et al. (2001) Fall risk assessment measures: an analytic review. J Gerontol A Biol Sci Med Sci 56: M761-766. [Crossref]

4. Cesari M, Landi F, Torre S, Onder G, Lattanzio F, et al. (2002) Prevalence and risk factors for falls in an older community-dwelling population. $J$ Gerontol A Biol Sci Med Sci 57: M722-726. [Crossref]

5. Rubenstein LZ (2006) Falls in older people: epidemiology, risk factors and strategies for prevention. Age Ageing 35 Suppl 2: ii37-37ii41. [Crossref]

6. Rubenstein LZ, Josephson KR (2002) The epidemiology of falls and syncope. Clin Geriatr Med 18: 141-158. [Crossref]

7. Sattin RW (1992) Falls among older persons: a public health perspective. Annu Rev Public Health 13: 489-508. [Crossref]

8. Dionyssiotis Y (2012) Analyzing the problem of falls among older people. Int J Gen Med 5: 805-813. [Crossref]

9. Lamontagne I, Lévesque B, Gingras S, Maurice P, Verreault R (2004) Environmental hazards for falls in elders in low income housing. Rev Epidemiol Sante Publique 52: 19-27. [Crossref]

10. ESC 2012. Guidelines for the management of acute myocardial infarction in patients presenting with ST segment elevation.

11. Babuin L, Jaffe AS (2005) Troponin: the biomarker of choice for the detection of cardiac injury. CMAJ 173: 1191-1202. [Crossref]

12. Bakshi TK, Choo MK, Edwards CC, Scott AG, Hart HH, et al. (2002) Causes of elevated troponin I with a normal coronary angiogram. Intern Med $J$ 32: 520-525. [Crossref]

13. Kelley WE, Januzzi JL, Christenson RH (2009) Increases of Cardiac Troponin in Conditions other than Acute Coronary Syndrome and Heart Failure. Clinical Chemistry 55: 2098-2112. [Crossref]

14. Jeremias A, Gibson CM (2005) Narrative review: alternative causes for elevated cardiac troponin levels when acute coronary syndromes are excluded. Ann Intern Med 142: 786-791. [Crossref]

15. Agewall S, Giannitsis E, Jernberg T, Katus H (2011) Troponin elevation in coronary vs. non-coronary disease. Eur Heart J 32: 404-411. [Crossref]

16. Wallace TW, Abdullah SM, Drazner MH, Das SR, Khera A, et al. (2006) Prevalence and determinants of troponin $\mathrm{T}$ elevation in the general population. Circulation 113 1958-1965. [Crossref]

17. (2000) Myocardial infarction redefined - a consensus document of The Joint European Society of Cardiology/American College of Cardiology Committee for the Redefinition of Myocardial Infarction. Eur Heart J 21:1502-1513.

18. Fromm RE (2007) Cardiac troponins in the elderly: interpretation of elevated levels Journal of Geriatric Cardiology 4: 188-192.

19. Nallet O (2010 ) La troponine aux urgences : Un biomarqueur trop utilisé. Journées Européennes de la Société française Cardiologie, Paris.

20. Baffoni L, Pedrazzi R, Neri R, Marzaloni M (2004) An unexpected increase of troponin I after perphenazine depot injection. Ann Pharmacother 38: 353-354. [Crossref]

21. Ronaldson KJ, Fitzgerald PB, Taylor AJ, Topliss DJ, McNeil JJ (2011) A new monitoring protocol for clozapine-induced myocarditis based on an analysis of 75 cases and 94 controls. Aust N Z J Psychiatry 45: 458-565. [Crossref]

22. Maréchaux S, Lubret R, Delsart P, Hattabi M, Six-Carpentier MM, et al. (2010) Clinical significance of unsuspected rise in cardiac troponin in the setting of falls in older people. Emerg Med J 27: 446-450. [Crossref]

23. Kontos MC, Anderson FP, Alimard R, Ornato JP, Tatum JL, et al. (2000) Ability of troponin I to predict cardiac events in patients admitted from the emergency department. J Am Coll Cardiol 36: 1818-1823. [Crossref]

24. Sandhu A, Sanders S, Geraci SA (2013) Prognostic value of cardiac troponins in 
elderly patients with hip fracture--a systematic review. Osteoporos Int 24: 1145-1149. [Crossref]

25. van Kimmenade RR, Januzzi JL Jr (2009) Whose heart will get broken? Troponin testing and future heart failure. Eur Heart $J$ 30: 755-756. [Crossref]

26. U.S. Renal data system: USRDS 2010 Annual report: Atlas of End Stage Renal Disease in the United States. Bethesda, MD: National institutes of Health, National Institute of Diabetes and Digestive and Kidney diseases 2010.
27. Turner AJ, Hick PE (1975) Inhibition of aldehyde reductase by acidic metabolites of the biogenic amines. Biochem Pharmacol 24: 1731-1733. [Crossref]

28. Buhaescu I, Izzedine H, Covic A (2005) Cardiac troponins in renal failure - time for an optimistic consensus? Int J Clin Pract 59: 1317-1325. [Crossref]

29. Khan NA, Hemmelgarn BR, Tonelli M, Thompson CR, Levin A (2005) Prognostic value of troponin $\mathrm{T}$ and I among asymptomatic patients with end-stage renal disease: meta-analysis. Circulation 112: 3088-3096. [Crossref]

Copyright: (2015 Nguyen C. This is an open-access article distributed under the terms of the Creative Commons Attribution License, which permits unrestricted use, distribution, and reproduction in any medium, provided the original author and source are credited. 